DOI 10.15393/j9.art.2019.5881

УДК 821.161.1.09“18”

Владимир Иванович Мельник

(Москва, Российская Федерачия)

melnikvi1985@mail.ru

\title{
Евангельская семантика женских образов Марфеньки и Веры в романе И. А. Гончарова «Обрыв»"
}

Аннотация. В статье впервые рассматривается евангельская основа образов Марфеньки и Веры в романе И. А. Гончарова «Обрыв». Подобно тому, как А. С. Пушкин оттенил идеальный образ Татьяны Лариной параллелью с ее сестрой Ольгой, Гончаров оттеняет образ Веры сопоставлением с Марфенькой. Основная тема романа - духовное состояние России, стоящей на краю «обрыва» (атеизма). Семантика имени одной из героинь - Вера - играет в романе важную смысловую роль, символизируя возможность спасения России, преодоления исторических «обрывов» с опорой на веру в Бога. Образы сестер указывают на два различных пути к святости: путь Марфы и путь Марии, описанные в Евангелии. Марфенька укрывается под сенью чужого авторитета и опыта, избегая искушения и ошибки. Вера проявляет самостоятельность, совершает ошибку, но - как сильная личность - находит в себе силы на покаяние и духовное «воскресение», повторяя судьбу бабушки и обнаруживая духовное сходство с нею. Женские образы, скрыто, но глубоко и последовательно соотнесенные с их евангельской первоосновой, являются в «Обрыве» одним из проявлений изменений в поэтике позднего Гончарова, более отчетливо демонстрирующего связь не только со Священным Писанием, но и с учением Святых Отцов Церкви о так называемой «духовной брани». В статье впервые анализируется попытка романиста, не выходя за рамки реализма, показать борьбу в человеческой душе «бесов» и Святого Духа. В последнем романе автор проявил себя не только как знаток, но и как тонкий толкователь Евангелия, показал духовные и психологические причины женской ошибки, что соотносится с судьбой евангельской Марии. Проекция на евангельские образы и реалистическое изображение "духовной брани» значительно меняют существующие представления о глубине духовного поиска Гончарова и проблематике романа «Обрыв».

Ключевые слова: Святой Дух, евангельские образы, архетип, Марфа, Мария, Гончаров, «Обрыв», Пушкин, «духовная брань»

о мнению В. А. Недзвецкого, «принципиальной особенно-
стью реалистической типизации Гончарова является все

(c) В. И. Мельник, 2019 
общественные приметы своего времени не просто широко, суммарно, но возводить их к неким “главным", или “коренным", “племенным", “основам" жизни в целом - русской и мировой» [Недзвецкий: 66]. Это утверждение можно дополнить тем, что количество «коренных типов», исчерпывающих человеческую природу в ее главных чертах, романист считал весьма ограниченным. Например, в письме к С. А. Никитенко от 21 августа (2 сентября) 1866 г. И. А. Гончаров заметил:

«Один Шекспир создал Гамлета, да Сервантес - Дон Кихота, и эти два гиганта поглотили в себе почти все, что есть комического и трагического в человеческой природе. А мы, пигмеи, не сладим со своими идеями - и оттого у нас есть только намеки»'

В статье «Лучше поздно, чем никогда» (1879) романист аналогично высказывается о главных женских типах в литературе, которым соответствуют и образы Марфеньки и Веры из романа «Обрыв» (1869):

«Надо сказать, что у нас, в литературе (да, я думаю, и везде), особенно два главные образа женщин постоянно являются в произведениях слова параллельно, как две противоположности: характер положительный - пушкинская Ольга и идеальный - его же Татьяна. Один - безусловное, пассивное выражение эпохи, тип, отливающийся, как воск, в готовую, господствующую форму. Другой - с инстинктами самосознания, самобытности, самодеятельности. Оттого первый ясен, открыт, понятен сразу (Ольга в «Онегине», Варвара в «Грозе»). Другой, напротив, своеобразен, ищет сам своего выражения и формы, и оттого кажется капризным, таинственным, малоуловимым $<\ldots>$...они же, смею прибавить, явились в моем “Обрыве”. Это два господствующие характера, на которые в основных чертах, с разными оттенками, более или менее делятся почти все женщины» [Гончаров. Лучше поздно....: 77-78].

Изображая «два господствующие характера» в своем последнем романе, Гончаров не копирует предшественников. Одним из определяющих в сюжете является мотив драматической ошибки, женского «обрыва» (бабушка и Вера), которым автор ставит вопрос о цене личностной самостоятельности 
женщины, обращаясь к евангельским архетипам Марфы и Марии.

Образы главных героинь «Обрыва» Марфеньки и Веры восходят к евангельским персонажам - сестрам Марфе и Марии (см.: [Мельник, 2002: 177]). Анализ данной параллели показывает не только то, как глубоко Гончаров знал Евангелие и как часто прибегал к его цитированию в своих художественных текстах, но и то, что писатель представляет в своем произведении развернутую проекцию на евангельский сюжет, обращаясь к его толкованию и указывая на духовные и психологические причины поведения Марии. Опора на Евангелие в трактовке женских характеров позволила Гончарову переосмыслить проблему женской эмансипации и ее отражение в русской литературе 1860-х гг.

Имя одной из героинь, Марфы (Марфеньки), полностью совпадает с евангельским, поскольку доминанта характера «многозаботливой» Марфы передана в романе почти без изменений. Евангельское имя Мария в романе заменено автором на Вера, поскольку для Гончарова было важно не столько подчеркнуть обращение к сакральным темам, сколько обозначить их, не делая культурных, исторических и иных параллелей слишком очевидными. Кроме того, это давало ему определенную свободу в обращении с материалом. Имя Веры играет в романе важную смысловую роль, так как спасение России, преодоление исторических «обрывов», по мнению автора, возможно лишь с опорой на веру в Бога.

Параллель с евангельскими образами в романе строится на важном для Гончарова контрасте двух различных моделей святости: «Марфа! Марфа! ты заботишься и суетишься о многом, а одно только нужно; Мария же избрала благую часть, которая не отнимется у неё» (Лк. 10:41-42). Толкование этих слов Христа известно: не сами заботы Марфы послужили причиной укорения, но духовное устроение девушки внешнему служению Христу (принять и накормить) ею отдавалось предпочтение перед служением внутренним (выслушать и исполнить слово Христа).

Марфенька в «Обрыве» принадлежит к числу тех натур, которые избегают искушения, живут природно данными 
добродетелями и послушанием старшим. Отсюда ее «солнечность», невинность и детскость, даже некоторая «растительность»: «...я вся вот из этого песочку, из этой травки!». «Ты вся - солнечный луч!» - говорит о ней Райский. У Марфеньки более прямой путь к Богу, чем у Веры. Размышляя о характерах сестер, Райский замечает: «Что это за нежное, неуловимое создание... какая противоположность с сестрой: та луч, тепло и свет; эта вся - мерцание и тайна, как ночь - полная мглы и искр, прелести и чудес!..» (7; 288). Природа «солнечного» образа Марфеньки заключается в том, что она не подвержена никакому искушению, сомнению, рефлексии. Она живет сердцем и традицией. В этом сильная сторона Марфеньки, но в этом же и причина того, что она лишена духовной порывистости, «пламенности» Веры («пассивное выражение эпохи, тип, отливающийся, как воск, в готовую, господствующую форму» [Гончаров. Лучше поздно...: 77]).

Вторая сестра, Вера, как и евангельская Мария, самостоятельна в мыслях и поступках, однако эта самостоятельность является и причиной духовной ошибки и женского падения, как Марии, так и Веры. Согласно Евангелию, Мария - покаявшаяся грешница, блудница: «Некто из фарисеев просил Его вкусить с ним пищи; и Он, войдя в дом фарисея, возлег. И вот, женщина того города, которая была грешница, узнав, что Он возлежит в доме фарисея, принесла алавастровый сосуд с миром и, став позади у ног Его и плача, начала обливать ноги Его слезами и отирать волосами головы своей, и целовала ноги Его, и мазала миром. Видя это, фарисей, пригласивший Его, сказал сам в себе: если бы Он был пророк, то знал бы, кто и какая женщина прикасается к Нему, ибо она грешница» (Лк. 7:36-39). Апостол Иоанн указывает, что эта грешница - сестра Лазаря: «Мария же, которой брат Лазарь был болен, была $m a$, которая помазала Господа миром и отерла ноги Его волосами своими» (Ин. 11:2)

Но Мария - грешница, восставшая против своего греха и избравшая «благую часть», слушающая слово Христа с бо́лышим рвением, чем ее добродетельная сестра Марфа. Эта любовь к Христу и его учению объясняется в 7-й главе Евангелия от Луки: «Иисус сказал: у одного заимодавца было два должника: 
один должен был пятьсот динариев, а другой пятьдесят, но как они не имели чем заплатить, он простил обоим. Скажи же, который из них более возлюбит его? Симон отвечал: думаю, тот, которому более простил. Он сказал ему: правильно ты рассудил <...> прощаются грехи её многие за то, что она возлюбила много ${ }^{4}$, а кому мало прощается, тот мало любит. Ей же сказал: прощаются тебе грехи <...>. Он <...> сказал женщине: вера твоя спасла тебя, иди с миром» (Лк. 7:41-43; 47-50). То есть именно ошибки и грехи Марии, прощаемые Христом, являются причиной того, что она «благую часть избра...». Гончаров воспроизвел парадокс евангельского образа Марии: она грешница, однако ее вера в Христа более осознанна и деятельна, а любовь к Нему более горяча, чем у ее сестры. В романе «Обрыв» совершенно очевидно, что, пережив падение, Вера будет более горяча и крепка в вере, чем неискушенная Марфенька, никогда не выходившая из послушания бабушке и жившая лишь преданием и традицией. Это подтверждает черновая редакция романа, где бабушка обращается к Богу с такими словами: «Пощади это дитя - милосердуй... Она, очищенная раскаянием, по слову Твоему, лучше многих праведниц теперь... милее Тебе своей безгрешной сестры, Твоей чистой лампады...» $\left(8_{1} ; 421-422\right)$.

Гончаров впервые показывает в «Обрыве» не столько душевную, сколько духовную сферу человеческой и общественной жизни, что определяет некоторые особенности поэтики романа. В «Обрыве» писатель пристально вглядывается в то, что стоит за видимым миром. Художник мотивирует поступки главных героев борьбой в их душе Святого Духа и беса-искусителя, впервые говоря о демонических силах почти в буквальном, не метафорическом смысле. Так, Райского на подлый поступок по отношению к Вере толкают бесы: «Бесы вторглись и рвали его внутренность» (7; 626). В третьей главе четвертой части автор снова указывает на духовную природу недуга Райского: «Другая мука, не вчерашняя, какой-то новый бес бросился в него...» $(7 ; 636)$. И здесь же: «Это был не я, не человек: зверь сделал преступление. Что это такое было!» $(7 ; 637)^{5}$. В черновом наброске к роману характерен диалог Веры и бабушки: 
«- Кто нам застилал глаза?

— Лукавый! <..> мне мешал угадать твое горе и отвести тебя. А тебя ослеплял гордостью! И кому попалась ты, бедная! <..> Взял свое враг рода человеческого!» $\left(8_{1} ; 425\right)$.

Бесам, или «зверю», противостоит в душе Райского Святой Дух. Гончаров обытовляет сакральные понятия и называет Святой Дух «таинственным» и «чистым». Райский, как пишет Гончаров,

«с ужасом вглядывался и вслушивался в дикие порывы животной, слепой натуры, сам писал ей казнь и чертил новые законы, разрушал в себе “ветхого человека" и создавал нового $<. .>$. Он, с биением сердца и трепетом чистых слез, подслушивал, среди грязи и шума страстей, подземную тихую работу в своем человеческом существе какого-то таинственного духа, затихавшего иногда в треске и дыме нечистого огня, но не умиравшего и просыпавшегося опять, зовущего его, сначала тихо, потом громче и громче, к трудной и нескончаемой работе над собой, над своей собственной статуей, над идеалом человека» (7; 553-554).

Обращаясь к такой тонкой материи, как действие Божьей силы в душе человека, Гончаров, в духе Священного Писания (3 Цар. 19:11-12; Лк. 8:23-24), противопоставляет «бурю» и «тишину»:

«С тайным, захватывающим дыхание ужасом счастья видел он, что работа чистого гения не рушится от пожара страстей, а только останавливается, и когда минует пожар, она идет вперед, медленно и туго, но всё идет <...>.

Пробегая мысленно всю нить своей жизни, он припоминал, какие нечеловеческие боли терзали его, когда он падал, как медленно вставал опять, как тихо чистый дух будил его, звал вновь на нескончаемый труд, помогая встать, ободряя, утешая, возвращая ему веру в красоту правды и добра и силу - подняться, идти дальше, выше...

Он благоговейно ужасался, чувствуя, как приходят в равновесие его силы, и как лучшие движения мысли и воли уходят туда, в это здание, как ему легче и свободнее, когда он слышит эту тайную работу и когда сам сделает усилие, движение, подаст камень, огня и воды» $(7 ; 554)$. 
В этом отрывке у Гончарова нет ничего случайного. Внутренняя работа по переделке человека из плотского в духовного, из ветхого в нового невозможна без Святого Духа, но также невозможна и без усилий самого человека, что подчеркнуто романистом употреблением именно этого слова («сам сделает усилие»). Усилие же это обозначено как соработничество Святому Духу: Он творит человека, а человек выступает как помощник - не творит, но подает «материалы». Сама образная система («камень, огонь, вода» - апокрифические образы, стилизованные под библейские ${ }^{6}$ да и весь смысл сказанного не оставляют сомнений, что речь идет о «творении нового человека из ветхого», о выработке в человеке идеала гармонии и красоты через действие в его душе Святого Духа, как это описано в трудах Отцов Церкви7. Так далеко в описании внутренней работы человека над самим собой - и притом через посредство Святого Духа, осеняющего каждую человеческую душу, - не заходил ни один русский художник ${ }^{8}$.

Поскольку доминирующим объектом изображения становится духовная жизнь человека, обращение Гончарова в «Обрыве» как к новозаветным, так и к ветхозаветным параллелям было неизбежным (см.: [Мельник, 2019: 335-342]). Для понимания духовной, а не только нравственной, основы образов идеальной Веры и «солнечной» (идеальной же) Марфеньки параллели с Татьяной и Ольгой Лариными романисту было бы явно недостаточно. При этом Гончаров показывает себя не только знатоком, но и тонким толкователем Евангелия, ибо задумывается о причинах и последствиях ошибки евангельской Марии. В образе Веры он показывает тот момент жизни Марии, который она пережила до падения. Романист пытается понять психологический «механизм» падения умной и чистой женщины - и видит причину в духовной неопытности, в том, что Святые Отцы называют «самостью»: в гордой, хотя и благородной, исполненной любви, попытке исправления чужой души в духе христианского идеала. В то же время, выстраивая свое "художественное богословие», Гончаров открывает собственное понимание слов Христа: «...прощаются грехи её многие за то, что она возлюбила много...» (Лк. 7:47). Любовь Веры к Марку Волохову жертвенна, поскольку она 
надеется именно любовью возвратить его к вере и истине 9 . «Возлюбила много» в данном контексте означает жертвенно, спасительно для другой души - с риском утратить свою ${ }^{10}$. Вот почему бабушка говорит о себе и о Вере: «Милосердуй над нами, над нашей слабостью... Мы не продались, мы не лгали, мы любили и ослабели... грешные создания...» $\left(8_{1} ; 421\right)$. Хотя Вера самонадеянна и горда в своей любви, но любит она жертвенно. Ее духовная ошибка, как и у Тамары в «Демоне» М. Ю. Лермонтова (см. об этом: [Мельник, 1997]), связана с тем, что она взяла на себя непосильную ношу: спасать и вести к вере другого, не будучи совершенной сама, духовно руководить, не пройдя уроков послушания (бабушке), не умея распознать неисправимого «духа зла». Таков же, по Гончарову, был путь евангельской Марии. По этой причине «прощаются грехи ее многие» и поэтому, по словам бабушки, Вера, пройдя путь греха и покаяния, «лучше многих праведниц теперь... милее Тебе своей безгрешной сестры» $\left(8_{1} ; 421-422\right)$.

Таким образом, создавая свой оригинальный вариант «двух господствующих характеров», Гончаров подчеркнул в выделенных им женских типах духовное начало - и обозначил духовные же различия между ними, внеся в пушкинскую трактовку существенные изменения. А. С. Пушкин воздвиг русской женщине памятник в лице Татьяны. Гончаров создал не менее величественный и драматичный образ женщины, пережившей ошибку, но раскаявшейся и нашедшей в себе силы подняться. Истоки этого образа он нашел в Евангелии.

Мотивы греха, покаяния и духовного воскресения связаны в романе не только с образом Веры, но и других главных героев - бабушки, Райского. Рядом с кающимися героями Гончаров изображает персонажей, которые не переживают искушений и чья духовная природа устроена очень счастливо, «солярно». Это прежде всего Марфенька и Тушин. Эти герои романа живут согласно словам из Первого послания апостола Петра: «Бог гордым противится, а смиренным дает благодать» (1 Петр. 5:5; см. также: Иак. 4:6). Задача Марфеньки и Тушина - не растерять того, что вложили в них природа и Бог. В статье «Лучше поздно, чем никогда» Гончаров писал о Тушине: «Природа дала ему талант быть человеком - 
и ему оставалось не портить этого...» [Гончаров. Лучше поздно...: 100]. Просветитель Штольц в романе «Обломов» утверждал, что человек создан «менять свою природу» (4; 391). Совсем иное дело - Тушин:

«А Тушин держится на своей высоте и не сходит с нее. Данный ему талант - быть человеком - он не закапывает, а пускает в оборот, не теряя, а только выигрывая от того, что создан природою, а не сам сделал себя таким, каким он есть» (7; 734-735).

Гончаров показывает, что духовно воскресающие герои Богу дороже, нежели не впадающие в грех как не пережившие искушения. В этом писатель следовал евангельской притче о заблудшей овце: «Сказываю вам, что так на небесах более радости будет об одном грешнике кающемся, нежели о девяноста девяти праведниках, не имеющих нужды в покаянии» (Лк. 15:7). Отношение к падшей Вере можно дополнить словами Евангелия от Матфея: «Смотрите, не презирайте ни одного из малых сих; ибо говорю вам, что Ангелы их на небесах всегда видят лице Отца Моего Небесного. Ибо Сын Человеческий пришел взыскать и спасти погибшее» (Мф. 18:1011). Вера не только прощена автором, но и возведена на нравственную высоту. Это выражается в том, что и сама Вера не презирает бабушку за падение, называя ее святой.

«Художественное богословие» писателя в его последнем романе целиком построено на евангельских принципах. Роман «Обрыв» доказывает, что Гончаров обладает системным и завершенным христианским мировидением, изображая человека в трех важнейших фазисах его жизни: грех - покаяние духовное воскресение ${ }^{11}$. Именно эта антропологическая модель просматривается в вершинных произведениях русской литературы. Гончаров сознавал значительность своего замысла и, заканчивая роман, писал редактору «Вестника Европы» М. М. Стасюлевичу: «У меня мечты, желания и молитвы Райского кончаются, как торжественным аккордом в музыке, апофеозом женщин, потом родины России, наконец Божества и Любви... Я < ..> боюсь, что маленькое перо мое не выдержит, не поднимется на высоту моих идеалов - и художественнорелигиозных настроений...» ${ }^{12}$. Религиозность писателя в его 
последнем романе уже не отрицается современным литературоведением, но почти не исследуется в своей конкретике. Как правило, в существующих работах о Гончарове подчеркивается лишь общий религиозный и антинигилистический настрой автора «Обрыва», указываются отдельные религиозные мотивы [Доманский], [Старыгина], [Щеблыкин]. Слова Гончарова о «высоте <...> художественно-религиозных настроений» в этом случае остаются лишь «фигурой речи». Между тем развернутая проекция на евангельские образы носит не «реминисцентный», а вполне концептуальный характер, а не замечаемое ранее реалистическое изображение «духовной брани» свидетельствует о том, что в последнем романе на глубокой христианской основе зиждется самая антропология человека. Очевидно и другое: изображая «духовную брань», Гончаров обнаруживает органичное усвоение писаний Святых Отцов Церкви. Все это существенно меняет общепринятые представления о глубине духовного поиска Гончарова и проблематике романа «Обрыв».

\section{Примечания}

* Исследование выполнено при финансовой поддержке РФФИ, проект № 17-04-50064.

1 Гончаров И. А. Избранные письма // Гончаров И. А. Собр. соч.: в 8 т. М.: ГИХЛ, 1955. Т. 8. С. 366.

2 Гончаров И. А. Полн. собр. соч. и писем: в 20 т. СПб.: Наука, 2004. Т. 7. С. 251. Далее ссылки на это издание приводятся в тексте статьи с указанием тома, книги (нижний индекс) и страницы в круглых скобках.

3 Толкователь Евангелия от Луки Феофилакт Болгарский писал: «Многих занимает вопрос: сколько было жен, помазавших Господа миром? Одни говорят, что их было две: одна - упоминаемая в Евангелии от Иоанна, сестра Лазаря (Ин. 12:3), и другая - та, о которой упоминают евангелисты Матфей (Мф. 26:6-7) и Марк (Мк. 14:3), и <...> Лука. Но я верю тем, кои говорят, что их (жен, помазавших Господа миром) было три: одна - сестра Лазаря, упоминаемая у Иоанна, помазавшая Господа за шесть дней до Пасхи, другая, - упоминаемая у Матфея и Марка, помазавшая за два дня до Пасхи, и третья - сия, упоминаемая теперь Лукой, помазавшая Господа в средине евангельской проповеди. И ничего нет странного, что она сделала это еще прежде, чем настало время страдания, а те сделали то же самое близ времени страдания, из подражания ей или по другому побуждению» [Блаженный Феофилакт: 380]. Очевидно, что Гончаров не придает разногласиям принципиального значения и, решая свои художественные 
задачи, сочетает версии Евангелия от Иоанна и Евангелия от Луки.

4 Очевидно, что Христос имеет в виду любовь истинную, хотя и приведшую к ошибке. Об этом в «Дневнике писателя» (май 1876 г.) размышлял Ф. М. Достоевский: «Г-н защитник в конце своей речи применил к своей клиентке цитату из Евангелия: “она много любила, ей многое простится”. Это, конечно, очень мило. Тем более, что г-н защитник отлично хорошо знает, что Христос вовсе не за этакую любовь простил “грешницу”. Считаю кощунством приводить теперь это великое и трогательное место Евангелия; вместо этого не могу удержаться, чтобы не привести одного моего давнишнего замечания, очень мелкого, но довольно характерного. Замечание это, разумеется, нисколько не касается г-на Утина. Я заметил еще с детства моего, с юнкерства, что у очень многих подростков, у гимназистов (иных), у юнкеров (побольше), у прежних кадетов (всего больше) действительно вкореняется почему-то с самой школы понятие, что Христос именно за эту любовь и простил грешницу, то есть именно за клубничку или, лучше сказать, за усиленность клубнички, пожалел, так сказать, привлекательную эту немощь. Это убеждение встречается и теперь у чрезвычайно многих. Я помню, что раз-другой я даже задавал себе серьезно вопрос: отчего эти мальчики так наклонны толковать в эту сторону это место Евангелия? Небрежно ли их так учат закону Божию? Но ведь остальные места Евангелия они понимают довольно правильно. Я заключил, наконец, что тут, вероятно, действуют причины более, так сказать, физиологические: при несомненном добродушии русского мальчика тут, вероятно, как-нибудь тоже действует в нем и тот особый избыток юнкерских сил, который вызывается в нем при взгляде на всякую женщину. А впрочем, чувствую, что это вздор, и не следовало бы приводить вовсе. Повторяю, г-н Утин, уж конечно, отлично знает, как надо толковать этот текст, и для меня сомнения нет, что он просто пошутил в заключение речи, но для чего - не знаю» (Достоевский Ф. М. Полн. собр. соч.: в 30 т. Л.: Наука, 1981. Т. 23. С. 19-20).

5 Гончаров употребляет слово «бесы» в сочетании со словами «бросились в него», «вторглись». Не приходя к прямой мистике, он в других случаях смягчает художественное впечатление, отмечая, что в Райского «вторглись» «холод, отвращение и злоба».

6 В Книге Бытия в Ветхом Завете образы если не камня, то «тверди», образы воды и огня играют важнейшую роль как главные «строительные материалы» создаваемого мира: «...Дух Божий носился над водою». (Быт. 1:2); «И сказал Бог: да будет твердь посреди воды, и да отделяет она воду от воды. [И стало так.] И создал Бог твердь, и отделил воду, которая под твердью, от воды, которая над твердью. И стало так». (Быт. 1:6-7). Кроме того, в Ветхом Завете Дух описывается в неживых образах мира материи: дыхания жизни, ветра, огня, воды и облака. Таким образом, огонь и вода - это не только «строительные материалы» для созидания мира и человека, но и образы, ассоциирующиеся 
с Самим Духом. Впрочем, очевидно, что Гончаров здесь берет лишь дух Ветхого Завета, но, по сути, пользуется апокрифическим осмыслением темы (ср. апокриф «Сказание, как сотворил Бог Адама». Человек, согласно этому апокрифу, создавался из земли (тело), камня (кости), моря (кровь), солнца (очи) и т. д.).

7 Г. Федотов в работе «О Святом Духе в природе и культуре» (1932) писал: «...в икономии Церкви Дух Святой остается самой таинственной ипостастью. Богословы согласны в том, что природа и действие Св. Духа являются для нас сокровенными, едва именуемыми» [Федотов: 232].

8 Хотя сама тема была обозначена, например, в стихотворении В. А. Жуковского «Мысли (Из Гёте)»: «Будь не солнечен наш глаз - / Кто бы солнцем любовался? Не живи дух Божий в нас - / Кто 6 божественным пленялся?» (Жуковский В. А. Полн. собр. соч. и писем: в 20 т. М.: Языки русской культуры, 2000. Т. 2: Стихотворения. 1815-1852. С. 264).

9 Впервые к теме женской самонадеянности в любви и неподготовленных попыток исправить любимого Гончаров подошел в «Обломове», где Ольга Ильинская пытается «поднять» Обломова с дивана:

«И всё это чудо сделает она, такая робкая, молчаливая, которой до сих пор никто не слушался, которая еще не начала жить! Она - виновница такого превращения!

Уж оно началось: только лишь она запела, Обломов - не тот...

Он будет жить, действовать, благословлять жизнь и ее. Возвратить человека к жизни - сколько славы доктору, когда он спасет безнадежного больного! А спасти нравственно погибающий ум, душу?..

Она даже вздрагивала от гордого, радостного трепета; считала это уроком, назначенным свыше» $(4 ; 205)$.

10 О любви Марфеньки Гончаров писал в статье «Лучше поздно, чем никогда»: «...взаимная, веселая и ясная, как весна, любовь Викентьева и Марфеньки, внушенная и лелеемая самою природою, как любовь птиц, осмысленная их светлым, естественным взглядом на жизнь и друг на друга» [Гончаров. Лучше поздно....: 103].

11 Как известно, в современной науке дискутируется вопрос о том, что считать последовательным выражением христианского мировоззрения у художников (см.: [Любомудров: 364]). Нам кажется, прав В. Н. Захаров, когда пишет: «...прежде чем спорить, необходимо условиться, что понимать под Православием. Для А. М. Любомудрова и В. М. Лурье Православие - догматическое учение, и его смысл определен катехизисом. При таком подходе православными могут быть только духовные сочинения. Между тем Православие не только катехизис, но и образ жизни, мировосприятие и миропонимание народа. В этом недогматическом смысле говорят о православной культуре и литературе, о православном человеке, народе, мире и т. п.» [Захаров: 6]. Напомним и слова Н. Лосского: «Бесконечно сложное содержание Божественной правды, лежащей в основе христианства, не вмещается в ограниченном сознании земного человека. Многие великие философы и многие 
гениальные художники стремились выразить эту правду в своем творчестве, но все эти попытки далеки от совершенства: в каждой из них воплощены лишь те или другие стороны всеобъемлющей Божественной истины, но, оторванные от целого, они легко подвергаются искажениям. Поэтому видов христианского миропонимания много и каждый из них содержит в себе своеобразные недостатки, обусловленные неполнотою» [Лосский: 133].

12 Гончаров И. А. Избранные письма. С. 386.

\section{Список литературы}

1. Гончаров И. А. Лучше поздно, чем никогда: (Критические заметки) // Гончаров И. А. Собр. соч.: в 8 т. - М.: ГИХЛ, 1955. - Т. 8. - С. 64-113.

2. Доманский В. А. Сады романа «Обрыв»: эдем, потерянный и возвращенный рай // И. А. Гончаров: (Материалы Междунар. науч. конф., посвящ. 195-летию со дня рождения И. А. Гончарова). Сб. ст. рус. и зарубеж. авт. / сост. А. В. Лобкарева, И. В. Смирнова, Е. Б. Клевогина. - Ульяновск, 2008. - С. 167-176.

3. Захаров В. Н. Православные аспекты этнопоэтики русской литературы // Проблемы исторической поэтики. - Петрозаводск: Изд-во ПетрГУ, 1998. - Вып. 5. - С. 5-30 [Электронный ресурс]. — URL: http://poetica. pro/journal/article.php?id=2472 (22.12.2018). DOI: 10.15393/j9.art.1998.2472

4. Лосский Н. О. Достоевский и его христианское миропонимание. Нью-Йорк: Изд-во имени Чехова, 1953. — 406 с.

5. Любомудров А. М. Православное монашество в творчестве и судьбе И. С. Шмелева // Русская литература и христианство. - СПб., 1994. С. 364-394.

6. Мельник В. И. «Свою Тамару не брани...» (Лермонтовская тема в «Обрыве» И. А. Гончарова) // Филологические записки. Вестник литературоведения и языкознания. - Воронеж: Изд-во ВГУ, 1997. Вып. 9. - С. 53-67.

7. Мельник В. И. И. А. Гончаров: духовные и литературные истоки. Монография. - М.: Изд-во МГУП, 2002. - 284 с.

8. Мельник В. И. Духовный путь И. А. Гончарова. - М.: Вече, 2019. - 448 с.

9. Недзвецкий В. Психологическое течение в литературе критического реализма (Гончаров) // Развитие реализма в русской литературе: в 3 т. М.: Наука, 1973. - Т. 2. - Кн. I. - 388 с.

10. Старыгина Н. Н. Демонические знаки в антинигилистическом романе как выражение авторской ценностно-мировоззренческой позиции // Проблемы исторической поэтики. - Петрозаводск, 1998. Вып. 5. -С. 204-222 [Электронный ресурс]. - URL: http://poetica.pro/ journal/article.php?id=2493 (22.12.2018). DOI: 10.15393/j9.art.1998.2493

11. Щеблыкин И. П. Мотив «греховности» и вины в романе И. А. Гончарова «Обрыв» // И. А. Гончаров: (Материалы международной конференции, посвящ. 180-летию со дня рождения И. А. Гончарова). — Ульяновск, 1994. — С. 204-212. 
12. Федотов Г. П. О Св. Духе в природе и культуре // Федотов Г. П. Собр. соч.: в 12 т. - М.: Мартис, 1998. - Т. 2. - С. 232-244.

13. Феофилакт Болгарский (блаженный). Толкование блаженного Феофилакта архиепископа Болгарского на книги Нового Завета. - M.: Директ-Медиа, 2014. 2006 с. [Электронный ресурс]. - URL: http:// azbyka.ru (22.12.2018).

Информация об авторе: Мельник Владимир Иванович - доктор филологических наук, член-корреспондент АН Республики Татарстан.

Дата поступления в редакиию: 16.01.2019

Дата публикаици: 29.03.2019

Vladimir I. Mel'nik

(Moscow, Russian Federation)

melnikvi1985@mail.ru

\section{The Evangelical Semantics of the Female Images of Martha and Vera in the Novel "The Precipice" by I. A. Goncharov}

Acknowledgments. The reported study was funded by RFBR according to the research project no. 17-04-50064.

Abstract. The article for the first time studies the gospel basis of the images of Marthenka and Vera in I. A. Goncharov's novel "The Precipice”. Just as Pushkin highlighted an ideal image of Tatyana Larina comparing it to that one of her sister Olga, Goncharov emphasizes the personality of Vera by contrasting her with Martha. The main theme of the novel is a spiritual order of Russia that is on the brink of a "precipice" (i. e. atheism). The meaning of the name of one of the protagonists - Vera, that is Faith, - plays an important semantic role in the novel, symbolizing a possibility of the salvation of Russia, overcoming of the historical "precipices" based on faith in God. The sisters' images point to two different paths to Holiness: the path of Martha and the path of Mary, described in the gospel. Marthenka hides under the shadow of someone else's authority and experience, avoiding thus temptation and mistakes. Vera shows herself independent, makes a mistake, but being a strong person finally finds strength to come into repentance and spiritual "resurrection", repeating the destiny of the grandmother and showing the signs of spiritual similarity with her. Women's images, hidden, but deeply and consistently correlated with their Evangelical basis, are in "The Precipice" only a private manifestation of systemic changes in the poetics of the late Goncharov, more openly than before, demonstrating the connection not only with the Holy Scripture, but also with the teaching of the Holy Fathers of the Church about the so-called "spiritual warfare". The article for the first time reveals the novelist's attempt, without going beyond realism, to show the struggle in the human soul between the "demons" and the Holy spirit. In Goncharov's early literary texts there are also 
Evangelical reminiscences. But in his last novel, the writer manifests himself not only as an expert, but also as a great interpreter of the gospel, which showed the spiritual and psychological reasons of women's mistakes that is related to the destiny of the Evangelical Mary. The projection on the Evangelical images and the realistic representation of a spiritual battle significantly change the existing ideas about the depth of Goncharov's spiritual search and the problems of the novel "The Precipice".

Keywords: Holy Spirit, Evangelical images, archetype, Martha, Mary, Goncharov, "The Precipice", Pushkin, spiritual struggle

\section{References}

1. Goncharov I. A. Better Late Than Never: (Critical Notes). In: Goncharov I. A. Sobranie sochineniy: $v 8$ tomakh [Goncharov I. A. Collected Works: in 8 Vols]. Moscow, Gosudarstvennoe izdatel'stvo khudozhestvennoy literatury Publ., 1955, vol. 8, pp. 64-113. (In Russ.)

2. Domanskiy V. A. The Gardens of the Novel "The Precipice": Eden, Paradise Lost and Regained. In: I. A. Goncharov: (Materialy Mezhdunarodnoy nauchnoy konferentsii, posvyashchennoy 195-letiyu so dnya rozhdeniya I. A. Goncharova). Sbornik statey russkikh i zarubezhnykh avtorov [I. A. Goncharov: (Proceedings of the International Scientific Conference Devoted to the 195th Anniversary Since the Birth of I. A. Goncharov). Collection of the Articles of Russian and Foreign Authors]. Ulyanovsk, 2008, pp. 167-176. (In Russ.)

3. Zakharov V. N. Orthodox Aspects of the Ethnopoetics of Russian Literature. In: Problemy istoricheskoy poetiki [The Problems of Historical Poetics]. Petrozavodsk, PetrSU Publ., 1998, issue 5, pp. 5-30. Available at: http:// poetica.pro/journal/article.php?id=2472 (accessed on December 22, 2018). DOI: 10.15393/j9.art.1998.2472 (In Russ.)

4. Losskiy N. O. Dostoevskiy i ego khristianskoe miroponimanie [Dostoevsky and His Christian Understanding of the World]. New York, Izdatel'stvo imeni Chekhova Publ., 1953. 406 p. (In Russ.)

5. Lyubomudrov A. M. Orthodox Monasticism in the Works and Destiny of I. S. Shmelev. In: Russkaya literatura i khristianstvo [Russian Literature and Christianity]. St. Petersburg, 1994, pp. 364-394. (In Russ.)

6. Mel'nik V. I. "Do Not Come Down on Your Tamara..." (The Lermontov Theme in "The Precipice" by I. A. Goncharov. In: Filologicheskie zapiski. Vestnik literaturovedeniya i yazykoznaniya [Philological Notes. Bulletin of Literary Studies and Linguistics]. Voronezh, Voronezh State University Publ., 1997, issue 9, pp. 53-67. (In Russ.)

7. Mel'nik V. I. I. A. Goncharov: dukhovnye i literaturnye istoki. Monografiya [I. A. Goncharov: Spiritual and Literary Sources. Monograph]. Moscow, Moscow State University of Printing Arts Publ., 2002. 284 p. (In Russ.)

8. Mel'nik V. I. Dukhovnyy put' I. A. Goncharova [Goncharov's Spiritual Path]. Moscow, Veche Publ., 2019. 448 p. (In Russ.)

9. Nedzvetskiy V. A Psychological Course in the Literature of Critical Realism (Goncharov). In: Razvitie realizma v russkoy literature: $v 3$ tomakh [Development 
of Realism in Russian Literature: in 3 Vols]. Moscow, Nauka Publ., 1973, vol. 2, book 1.388 p. (In Russ.)

10. Starygina N. N. Demonic Signs in the Anti-Nigilistic Novel as an Expression of the Author's Value and Worldview Position. In: Problemy istoricheskoy poetiki [The Problems of Historical Poetics]. Petrozavodsk, PetrSU Publ., 1998, issue 5, pp. 204-222. Available at: http://poetica.pro/journal/article_en.php?id=2493 (accessed on December 22, 2018). DOI: 10.15393/j9.art.1998.2493 (In Russ.)

11. Shcheblykin I. P. The Motif of a "Sin" and Guilt in I. A. Goncharov's Novel "The Precipice". In: I. A. Goncharov: (Materialy mezhdunarodnoy konferentsii, posvyashchennoy 180-letiyu so dnya rozhdeniya I. A. Goncharova) [I. A. Goncharov: (Proceedings of the International Conference Devoted to the 180th Anniversary Since the Birth of I. A. Goncharov)]. Ulyanovsk, 1994, pp. 204-212. (In Russ.)

12. Fedotov G. P. About Saint Spirit in Nature and Culture. In: Fedotov G. P. Sobranie sochineniy: $v 12$ tomakh [Fedotov G. P. Collected Works: in 12 Vols]. Moscow, Martis Publ., 1998, vol. 2, pp. 232-244. (In Russ.)

13. Theophylact of Bulgaria (Blessed). Tolkovanie blazhennogo Feofilakta arkhiepiskopa Bolgarskogo na knigi Novogo Zaveta [Interpretation of the Blessed Theophylact Archbishop of Bulgaria on the Books of the New Testament]. Moscow, Direct Media Publ., 2014. 2006 p. Available at: http://azbyka.ru (accessed on December 22, 2018). (In Russ.)

Information about the author: Mel'nik Vladimir I. - Doctor of Philology, corresponding member of the Academy of Sciences of the Republic of Tatarstan.

Received: January 16, 2019 Date of publication: March 29, 2019 